\title{
Unified power flow controller (UPFC) integrated with electromagnetic energy storage system for system stability enhancement
}

\author{
Saravanan Kandasamy, Dawit Leykuen Berhanu, Getnet Zewde Somanu
}

Department of Electrical and computer Engineering, JIT, Jimma University, Jimma, Ethiopia

Email address:

Saravanan.me07@gmail.com (S. Kandasamy), dawitleykuen@yahoo.com (D. L. Berhanu), findgetnet@gmail.com (G. Z. Somanu)

To cite this article:

Saravanan Kandasamy, Dawit Leykuen Berhanu, Getnet Zewde Somanu. Unified Power Flow Controller (UPFC) Integrated with Electromagnetic Energy Storage System for System Stability Enhancement. American Journal of Electrical Power and Energy Systems. Vol. 3, No. 3, 2014, pp. 50-59. doi: 10.11648/j.epes.20140303.11

\begin{abstract}
In this paper analysis the UPFC integrated with energy storage devices for improvement of system stability compensation. Before that, used traditional UPFC is to control all transmission line parameters simultaneously or selectively but don't have appropriate control for throughout system. During large transients; traditional UPFC have restricted capability of power flow control. In this paper to do reduce or eliminate that negative aspect of established UPFC using substantial energy storage devices adapted with UPFC. In this proposed system Integration of Superconducting Magnetic Energy Storage (SMES) into UPFC is described. SMES is connected to UPFC through an interface with DC-DC chopper. UPFC with SMES system will inject or absorb real and reactive power to or from an influence system at really quick rate on a repetitive beginning of stability problem. Here Comparative Analysis of the two types, one is integration of electromagnetic energy storage into UPFC and another is integration of electrochemical energy storage into UPFC is done by means of MATLAB/SIMULINK software package.
\end{abstract}

Keywords: Transient Stability, Flexible AC transmission System, UPFC, SMES, Battery, DC-DC Chopper

\section{Introduction}

In sensible arrangement of nonlinear network mustn't maintain the stable condition attributable to explosive changes in load or increment of demand. Whenever load changes within the operating power grid, the system select instability state of affairs. Therein state of affairs compensation is required to keep up system stability. At the current time, usage of compensating device used for FACTS devices. The FACTS devices can give the lager quantity of power transfer capability within the power Network. UPFC is one in all the second generation FACTS devices. It's wont to management real and reactive power autonomously [1].

The existing FACTS device had some issues. One is Dc link electrical condenser of UPFC is capable of charging or discharging for compensating method. At the time of equalization method, the convertor loss is there in UPFC. Energy keep dc-link electrical condenser is lean to finish compensation below massive transient amount [2].Another one is that the great amount of load is disconnected from the road, speed of the generator can increase, and attributable to this reason additional energy or power can seem within the unit. At this condition the facility is absorbed from power grid to dc link electrical condenser through converters and/or power is provide to power grid through converters. Therefore energy provides to power grid or absorption from power grid is definite restricted price. So as to beat the higher than two disadvantages we are able to use substantial energy storage systems. In this energy storage systems, additional energy is keep and/or energy provide to system in step with needs of power grid [3].

The existing FACTS parts area unit extra to Energy storage devices to boost the facility system stability by active power exchange with power grid, Via Energy storage devices like flywheels, ultra-capacitors, batteries and SMES. These devices area unit differing in charging/discharging rate, energy density, voltage level, potency and economical concerns with one another [2].

If electro chemical battery is employed as a considerable power provide, it'll produce some issues like high ohmic resistance, higher ageing, high heating levels, and chemical process happens on electrodes. Electro chemical batteries aren't able to management high power levels for durable 
periods, Quick, deep discharges results in high heating levels clearly reduces battery period $[4,5,6]$. Lead acid (flooded type) battery storage system potency is $72-78 \%$, generation 1000-2000 cycles at 70\%depth of discharge [7]. Radical capacitors need to face the issues like low energy density, low voltage, and unable to use full energy spectrum etc [8].

Comparing with all alternative substantial energy provides SMES having the benefits of high energy density, quick response, high potency, minimum energy loss throughout the conversion etc, thus It are thought of because the best substantial energy provide which may be simply integrated with FACTS devices for enhancing transient stability. SMES also can be an honest resolution for raising the facility quality [9, 10, and 11]. Advances in each superconducting technologies and also the necessary power physics interface have created SMES a viable technology that may supply versatile, reliable, and fast-acting power compensation [12].

Very few researches solely administered in FACTS with Energy storage system. During this paper MATLAB/Simulink code for UPFC integrated with SMES is enforced. During this methodology of research scheme is employed for sweetening of transient stability. Planned system to analysis completely different fault condition (Three part fault) shows results of theoretical account. During this paper improvement of transient stability additionally power flow management and power internal control.

\section{UPFC Operation}

The universal and most versatile FACTS device is that the Unified Power Flow Controller (UPFC). UPFC is that the most promising device within the FACTS. It brings a replacement challenge in power natural philosophy and power grid style. The Unified Power Flow Controller (UPFC) has the flexibility to regulate the ability flow between the two buses of the transmission systems by three vital parameters like, electric resistance of conductor, voltage magnitude and phase angle.

The two basic parts of UPFC are two voltage supply converters with semiconductor devices having turn-off capability. They Series device and Shunt device, these converters are connected to every alternative with a typical dc link and these two voltage supply converters sharing a typical dc electrical device shown in fig. 1. The capability of energy storing is mostly tiny in dc electrical device .The dc electrical device permits the two-way flow of active power between the series output terminals of the SSSC and also the shunt output terminals of the STATCOM. One VSI is connected in shunt with line through the shunt electrical device. The opposite one is connected nonparallel with line through the series electrical device. VSC's are coupled along for a full of life power exchange between the two converters and additionally it will severally exchange reactive power with the AC system. The shunt device is primarily used for providing the real power demand of the series device at the common dc link terminal from the ac power grid. It will generate or absorb reactive power at its ac terminal, that is autonomous of the active power transfer to (or from) the dc terminal. Active power that was drawn by the shunt device ought to be capable the active power generated by the series device.

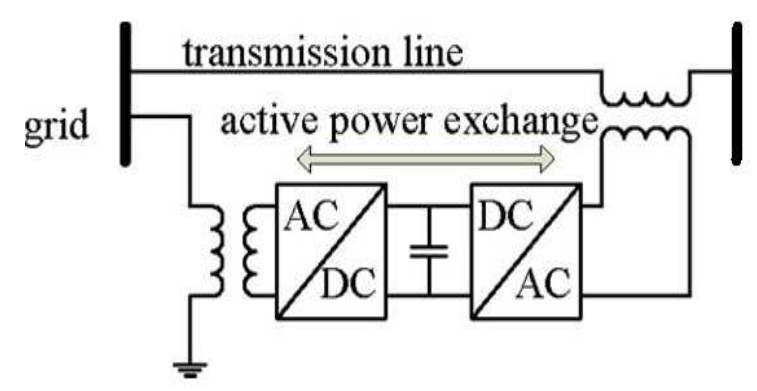

Figure 1. UPFC operation

The series-connected electrical converter injects a voltage with governable magnitude and phase nonparallel with the conductor, therefore providing real and reactive power to the conductor. The reactive power is electronically provided by the series electrical converter and then active power is transmitted to the dc terminals. Therefore the shunt electrical converter operated in such the way of keeping voltage across the dc electrical device $V_{d c}$ is constant. Therefore the web power absorbed by the road is capable the losses of the inverters and also the reactive power of their transformers.

The shunt-connected electrical converter provides the active power drawn by the series branch and the losses, and might severally give reactive compensation to the system. The remaining capability of shunt electrical converter is employed to exchange the reactive power among the road for the voltage regulation at the purpose. However, the injected active power ought to be equipped by DC link, successively taken from the AC system throughout the shunt device. Once the sufferers of the converters and also the associated transformers are neglected, then usually active power exchange between the UPFC and also the AC system becomes zero.

The reactive current I by

$$
\mathrm{I}=\frac{\mathrm{V}_{\mathrm{L}}-\mathrm{V}_{\mathrm{C}}}{\mathrm{X}}
$$

The corresponding reactive power $\mathrm{Q}$ exchanged can be expressed as follows:

$$
\mathrm{Q}=\frac{1-\frac{\mathrm{v}_{\mathrm{C}}}{\mathrm{V}_{\mathrm{L}}}}{\mathrm{X}} \mathrm{V}_{\mathrm{L}}^{2}
$$

Whereas $V_{L}$ is Transmission line voltage, $V_{C}$ is converter output voltage and $X$ reactance plus transformer leakage reactance plus system short circuit reactance.

\section{Energy Storage System}

ESSs is classified in to major three types, based on specific 
principles: 1) Physical energy storage including compressed air energy storage (CAES), flywheel energy storage (FES) and pumped hydro storage (PHS); 2) Electromagnetic energy storage including super-capacitor energy storage (SCES) and superconducting magnetic energy storage (SMES); 3) Electrochemical energy storage including lead-acid, Nickel Cadmium, lithium-ion, sodium sulfur and fluid flow battery energy storage, etc [19,20,21]. Physical energy storage is doesn't have a large-scale back-up [22]. The technologies of electrochemical energy storage, sodium-sulphur battery can efficiency of energy conversion reach $89 \%$ with the energy density three times as lead-acid battery and much longer life cycle. Research works about electromagnetic energy storage efficiency of energy conversion reach $95 \%$. The technology is energy saving and easy to operate with high efficiency [23, 24, $25,26]$.

\subsection{Integration of Energy Storage Systems into FACTS}

An energy storage system (ESS) will play a crucial role in power grid management and supply major enhancements over ancient UPFC performance. SMES in conjunction with UPFC have recently emerged together of the foremost promising near-term storage technologies for power applications. By the addition of an energy storage system to the UPFC it's been potential to manage the active power flow between the UPFC and also the purpose of common coupling (PCC). Thus, the UPFC compensates the reactive power and, additionally stores energy within the storage system once the generated power exceeds the facility limits that might be injected to the distribution grid. Additionally, this resolution provides promotes management of the facility flow at the PCC, by adjusting the direction of power injection, like down or upwards.

Recently, a substantial quantity of attention has been given to developing management ways for a spread of FACTS devices, like static synchronous compensator (STATCOM), the static synchronous series compensator (SSSC), and also the unified power flow controller (UPFC), to be ready to address and mitigate a large vary of potential bulk power transmission issues.

In the absence of energy storage, FACTS devices square measure restricted within the degree of freedom and sustained action during which they will facilitate the facility grid. By the tactic of integration of energy storage system (ESS) into FACTS devices, a freelance real and reactive power absorption or injection into and from the grid is feasible. This integrated system ends up in a lot of economical and versatile power transmission controller for the facility system. Once a line experiences vital power transfer variations in an intermittent manner, a FACTS + ESS combination is put in to manage and change the facility flow inside the loaded line. The improved superior performance of combined FACTS with ESS can have bigger charm to transmission service suppliers. Performance indices were planned for FACTS dynamic performance with energy storage in [27] and management schemes are mentioned in [28, 29 and 30].
Power system liberation, alongside transmission limitations and generation shortage, has modified the ability of grid conditions by making things wherever energy storage technology will play a really important role in maintaining system dependability and power quality. There are multiple edges of energy storage devices like the flexibility to apace damp oscillations, answer sharp load transients, and still offer the load throughout transmission or distribution interruptions. Additionally, this technique will correct load voltage profiles with fast reactive power management, and still enable the generators to balance with the system load at their traditional speed. Fig.1 presents typical design of connected UPFC with SMES to electrical utility system.

The main disadvantage of a conventional UPFC (with no energy storage) is that it's solely two potential steady-states in operation modes, namely, inductive (lagging) and electrical phenomenon (leading). although each the standard UPFC output voltage magnitude and phase will be controlled, they cannot be severally adjusted in steady state because of the shortage of great active power capability of UPFC. Typically, the UPFC device voltage is maintained in section with the PCC voltage, therefore making certain that solely reactive power flows from the UPFC to the system. However, as a result of some losses within the coupling electrical device and device, the device voltage is usually maintained with a little section shift with the PCC voltage. Thus, much, a little quantity of real power flows through the system from PCC to DC bus, to make amends for the losses. However, the $\$ 64000$ power capability of the UPFC is extremely restricted because of the absence of any energy storage the DC bus. Compared with the standard UPFC + BESS, the UPFC + SMES provide a lot of flexibility.

In case of UPFC with SMES, the amount of steady-state in operation modes is extended to varied things like inductive mode with DC charge and DC discharge, electrical phenomenon mode with DC charge and discharge. Thus, in steady state, the UPFC with SMES have four in operation modes and may operate at each purpose within the steady-state characteristic circle. Additionally, looking on the energy output of the battery or SMES, the discharge/charge profile is usually adequate to supply enough energy to stabilize the ability regulation within the system and maintain operation till alternative long energy sources are brought into operation.

One of the drawbacks of FACTS + ESS is that for FACTS integration, the scale of the storage systems, significantly battery energy storage (BESS), is also large for sensible use in large-scale transmission-level applications. On bound occasions, giant battery systems tend to exhibit voltage instability once varied cells are placed asynchronous. However, usually it's seen that even giant oscillations will be satisfied with modest power injection from a storage system. To cut back the drawbacks of the UPFC additional to BESS, we tend to use UPFC with SMES system. the flexibility to severally management each active and reactive powers in UPFC + SMES makes them ideal controllers for numerous styles of power regulation system applications, as well as 
voltage fluctuation mitigation and oscillation damping. Among them, the foremost necessary use of the UPFC + SMES is to stabilize any disturbances occurring within the installation.

\subsection{Integration of Energy Storage Systems into UPFC}

Comparative Analysis of the Two Types: 1) Electromagnetic energy storage 2) Electrochemical energy storage.

\subsection{Integration of Electromagnetic Energy Storage into UPFC}

In practical point of view SMES device is very costly compared to battery or ultra capacitor energy storage device. To eliminate these styles of drawback, SMES device connected in parallel with the FACTS. Block Diagram of Integrated UPFC with SMES shown in fig.2. In this system SMES device is generated the magnetic field, when flow of DC source through a superconducting coil. The UPFC model could be a combination of the static synchronous compensator (STATCOM) and static synchronous series compensator (SSSC) models. The currents and square measure the elements of the shunt current. The currents and square measure the elements of the series current. The voltages and square measure the causation finish and receiving finish voltage magnitudes and angles, severally. The UPFC parameters square measure the following:

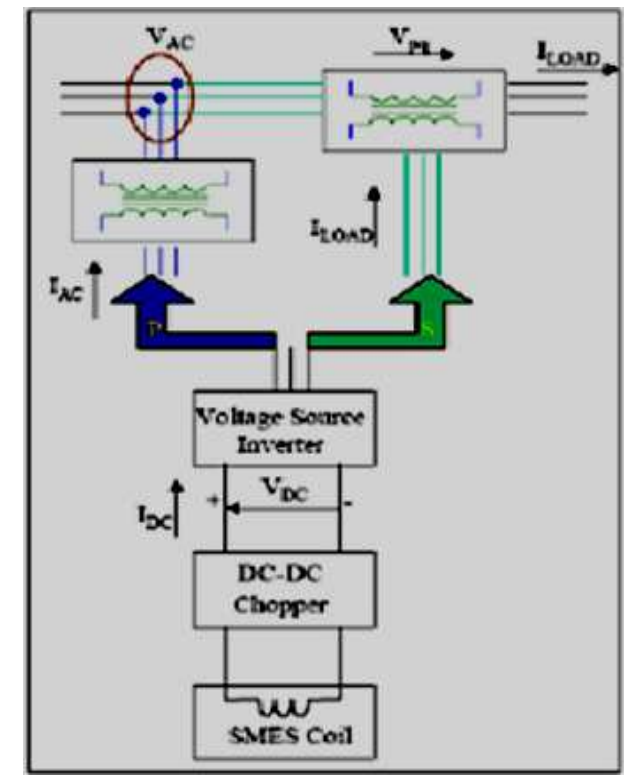

Figure 2. Block diagram of integrated UPFC with SMES

The power balance equations at bus 1 are given by

$$
\begin{aligned}
& 0=\mathrm{V}_{1}\left(\left(\mathrm{i}_{\mathrm{d} 1}-\mathrm{i}_{\mathrm{d} 2}\right) \cos \theta_{1}+\left(\mathrm{i}_{\mathrm{q} 1}-\mathrm{i}_{\mathrm{q} 2}\right) \sin \theta_{1}\right)-\mathrm{V}_{1} \sum_{\mathrm{j}=1}^{\mathrm{n}} \mathrm{V}_{\mathrm{j}} \mathrm{Y}_{1 \mathrm{j}} \cos \left(\theta_{1}-\theta_{\mathrm{j}}-\phi_{1 \mathrm{j}}\right) \\
& 0=\mathrm{V}_{1}\left(\left(\mathrm{i}_{\mathrm{d} 1}-\mathrm{i}_{\mathrm{d} 2}\right) \sin \theta_{1}-\left(\mathrm{i}_{\mathrm{q} 1}-\mathrm{i}_{\mathrm{q} 2}\right) \cos \theta_{1}\right)-\mathrm{V}_{1} \sum_{\mathrm{j}=1}^{\mathrm{n}} \mathrm{V}_{\mathrm{j}} \mathrm{Y}_{1 \mathrm{j}} \sin \left(\theta_{1}-\theta_{\mathrm{j}}-\phi_{1 \mathrm{j}}\right)
\end{aligned}
$$

And at bus 2

$$
0=\mathrm{V}_{2}\left(\mathrm{i}_{\mathrm{d} 2} \cos \theta_{2}+\mathrm{i}_{\mathrm{q} 2} \sin \theta_{2}\right) \mathrm{V}_{2} \sum_{\mathrm{j}=1}^{\mathrm{n}} \mathrm{V}_{\mathrm{j}} \mathrm{Y}_{2 \mathrm{j}} \cos \left(\theta_{2}-\theta_{\mathrm{j}}-\phi_{2 \mathrm{j}}\right)
$$

$$
\begin{gathered}
0=\mathrm{V}_{2}\left(\mathrm{i}_{\mathrm{d} 2} \cos \theta_{2}+\mathrm{i}_{\mathrm{q} 2} \sin \theta_{2}\right)-\mathrm{V}_{2} \sum_{\mathrm{j}=1}^{\mathrm{n}} \mathrm{V}_{\mathrm{j}} \mathrm{Y}_{2 \mathrm{j}} \cos \left(\theta_{2}-\theta_{\mathrm{j}}-\phi_{2 \mathrm{j}}\right) \\
0=\mathrm{V}_{2}\left(\mathrm{i}_{\mathrm{d} 2} \sin \theta_{2}+\mathrm{i}_{\mathrm{q} 2} \cos \theta_{2}\right)-\mathrm{V}_{2} \sum_{\mathrm{j}=1}^{\mathrm{n}} \mathrm{V}_{\mathrm{j}} \mathrm{Y}_{2 \mathrm{j}} \sin \left(\theta_{2}-\theta_{\mathrm{j}}-\phi_{2 \mathrm{j}}\right)
\end{gathered}
$$

\subsection{Basic Principles of the SMES Systems}

Electromagnetic ESS could be a reasonably energy storage instrumentation for changing the keep magnetic attraction energy into power directly with none intermediate transferring organizations. Generally, a SMES device consists of the superconducting coil, the refrigerant system, and also the power conversion/conditioning system (PCS) with filtering and protection functions. The coil in SMES doesn't lose Joule heat whereas poured into DC current, therefore the SMES device adopts DC charging supply system, and also the three-phase device transforms ac to dc and reverse. Reckoning on the management loop of its power conversion unit and switch characteristics, varieties of the coupling transformation embody two models: voltage supply device (VSC) and current supply device (CSC), through that SMES will well collaborate with the transmission network. Two-quadrant chopper consists of high power devices, though' that the coil is charged and discharged.

\subsection{Power Conditioning System}

A power acquisition system (PCS) is needed so as to transfer the energy from the SMES coil into the grid. A PCS consists of a dc-dc chopper and a 3 phase voltage source converter (VSC). Using the voltage-angle control strategy, both the active and reactive power can be controlled. A dc-dc chopper is mainly used to keep the current through the SMES coil constant and to transfer the power to the VSC through the dc-link capacitor. The SMES coil along with a dc-dc chopper is connected to the VSC through a dc-link capacitor. This capacitor acts as a temporary dc voltage source for the VSC to inject active/reactive power into the grid.

\subsection{Two Quadrant DC-DC Chopper}

In nonlinear grid, want of variable DC provide for improvement of system performance. Thus variable DC supply suggests that DC-DC chopper application. In DC-DC chopper some completely different varieties square measure there like one quadrant, two quadrants and four quadrants chopper. Regarding these varieties, two quadrants chopper was employed in this paper. Two quadrant choppers square measure connected in parallel with DC link electrical condenser of UPFC. SMES device have three modes of operation. 1st mode is charging of superconducting coil, second mode is energy standby in coil, and third mode is discharging of coil.

$$
\begin{gathered}
E_{\text {smes }}=\frac{1}{2} L_{\text {smes }} I_{\text {smes }}^{2} \\
P_{\text {smes }}=\frac{d E_{\text {smes }}}{d t}=L_{\text {smes }} I_{\text {smes }} \frac{d I_{\text {smes }}}{d t}=V_{\text {smes }} I_{\text {smes }}
\end{gathered}
$$




\subsubsection{SMES Charging Mode}

In this mode shown in Fig.3 (a), the SMES coil is charged to its rated capability. Throughout charging mode, GTO2 is often within the ON state. GTO1 are often switched ON or OFF in each cycle. The SMES coil charges once the GTO1 is additionally within the ON state. Once the SMES coil is charging, the connection between the voltage across the SMES coil and also the voltage across the dc link condenser are often given as

$$
V_{S M E S}=D * V_{D C}
$$

Where $V_{S M E S}$ the voltage is across the SMES coil $V_{D C}$ is the voltage across the dc link capacitor and D is the duty cycle of the GTO1 (defined as the ratio of the GTO ON time to the total time for a complete cycle)

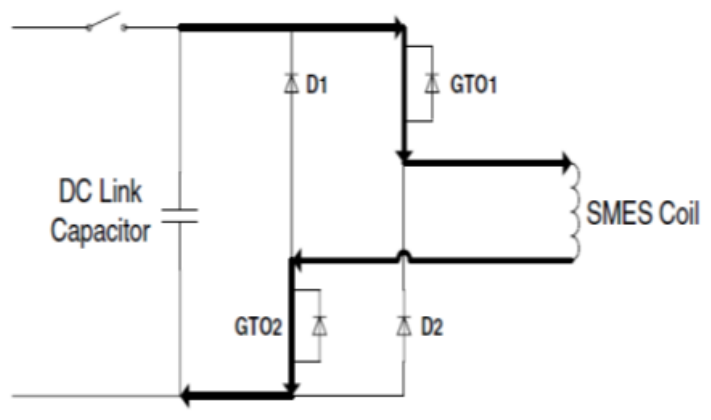

Figure 3 (a). Charging Mode

In this specific case, the duty cycle (D) of the GTO1 is unbroken constant at one second, so the SMES coil charges at the utmost charging rate potential. Within the gift simulation, it takes concerning three seconds to charge the coil to its rated current capability.

\subsubsection{SMES Standby Mode}

The second mode of operation is named the freewheeling mode. During this mode, the present circulates in a very closed-loop system. This can be additionally referred to as the standby mode. Once the SMES coil is within the freewheel mode, one amongst the 2 GTO's is OFF. In Fig. 3 (b), it absolutely was shown that GTO1 is ON and GTO2 is OFF. Throughout this era, there's no vital quantity of loss, because the current through the SMES coil is current in a very closed-loop system. Hence, the present remains fairly constant.

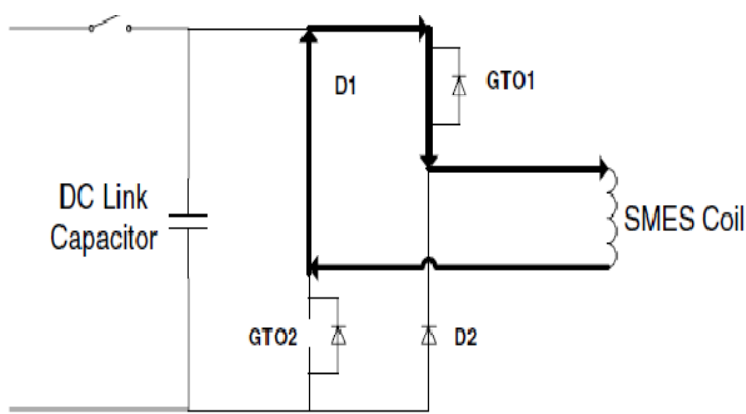

Figure 3 (b). Standby Mode

\subsubsection{SMES Discharge Mode}

The final mode of operation is that the discharge cycle. The present within the SMES coil discharges into the dc link electrical condenser during this mode of operation. During this mode shown in Fig.3 (c), the GTO2 is often within the OFF state and also the duty cycle of GTO1 will be varied counting on the speed of discharge demand. Throughout the discharge cycle, to own the utmost rate of discharge, each the GTOs square measure unbroken in OFF state. The speed of discharge of the SMES coil will be controlled by creating the duty cycle of 1 of the GTOs to be non-zero. The voltage relationship between the SMES coil and also the de link electrical condenser throughout the discharge cycle is given as

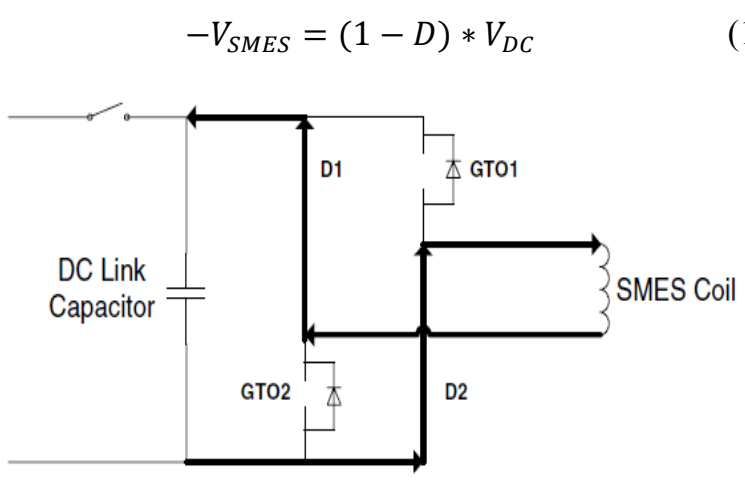

Figure 3(c). Discharge Mode

All the operative mode of DC-DC chopper shown in fig. $3(\mathrm{a}),(\mathrm{b}),(\mathrm{c})$, and also the initial mode of operation coil is charging, once giant capability of load is disconnected from the road. At that point of disconnection great amount of power flow in line, that power was absorbed from the road to store in coil. Whenever coil is storing, the voltage of the coil is positive. Second mode is holding on energy in standby mode, once facility is balanced condition. Third mode of operation coil is discharge, once masses square measure adding to the road or when faults clearing time. Throughout the addition of load, need a lot of power injection in line. This injection of additional power transferred from discharging of coil to line. Coil voltage is negative once coil is discharging.

\subsection{Integration of Electrochemical Energy Storage into UPFC}

UPFC Integration with battery energy device exploitation grid stability improvement. During this system battery is connected across the DC link electrical condenser of UPFC through DC-DC convertor. Whenever power systems lower load or no load condition, the road power flow is raised. The additional power is keep in battery from the line. Once line is want some further energy or power, at the amount of compensation the battery can discharge. Battery energy device isn't applicable for long-standing amount at high power levels. The battery charging and discharging amount chemical change is there. Attributable to chemical change additional thermal drawback in battery, therefore lifespan of the battery is reduced [7]. 
Table 1. Battery technologies—characteristics and commercial units used in electric utilities

\begin{tabular}{|c|c|}
\hline Battery type & Comments \\
\hline $\begin{array}{l}\text { Lead acid } \\
\text { (flooded type) }\end{array}$ & $\begin{array}{l}\eta=72-78 \% \text {, cost } 50-150 \text { Euro/kWh, life span } \\
1000-2000 \text { cycles at } 70 \% \text { depth of discharge, } \\
\text { operating temperature }-5 \text { to } 40 \circ \mathrm{C}, 25 \mathrm{Wh} / \mathrm{kg} \text {, } \\
\text { self-discharge } 2-5 \% / \text { month, frequent maintenance to } \\
\text { replace water lost in operation, deep. }\end{array}$ \\
\hline $\begin{array}{l}\text { Lead acid } \\
\text { (valve regulated) }\end{array}$ & $\begin{array}{l}\eta=72-78 \% \text {, cost } 50-150 \text { Euro } / \mathrm{kWh} \text {, life span } \\
200-300 \text { cycles at } 80 \% \text { depth of discharge, operating } \\
\text { temperature }-5 \text { to } 40 \circ \mathrm{C}, 30-50 \mathrm{Wh} / \mathrm{kg} \text {, } \\
\text { self-discharge } 2-5 \% / \text { month, less robust, negligible } \\
\text { maintenance, more mobile, safe (compared to } \\
\text { flooded type) }\end{array}$ \\
\hline $\begin{array}{l}\text { Nickel } \\
\text { Cadmium } \\
(\mathrm{NiCd})\end{array}$ & $\begin{array}{l}\eta=72-78 \% \text {, cost } 200-600 \text { Euro } / \mathrm{kWh} \text {, life span } \\
3000 \text { cycles at } 100 \% \text { depth of discharge, operating } \\
\text { temperature }-40 \text { to } 50 \circ \mathrm{C}, 45-80 \mathrm{Wh} / \mathrm{kg} \text {, } \\
\text { self-discharge } 5-20 \% / \mathrm{month} \text {, high discharge rate, } \\
\text { negligible maintenance, NiCd cells are poisonous } \\
\text { and heavy }\end{array}$ \\
\hline $\begin{array}{l}\text { Sodium Sulphur } \\
(\mathrm{NaS})\end{array}$ & $\begin{array}{l}\eta=89 \% \text { (at } 325 \circ \mathrm{C} \text { ), life span } 2500 \text { cycles at } 100 \% \\
\text { depth of discharge, operating temperature } 325{ }^{\circ} \mathrm{C} \text {, } \\
100 \mathrm{Wh} / \mathrm{kg} \text {, no self-discharge, due to high operating } \\
\text { temperature it has to be heated in stand-by mode and } \\
\text { this reduces its overall } \mathrm{n} \text {, have pulse power } \\
\text { capability of over } 6 \text { times their rating for } 30 \mathrm{~s}\end{array}$ \\
\hline Lithium ion & $\begin{array}{l}\eta \approx 100 \% \text {, cost } 700-1000 \text { Euro/kWh, life span } 3000 \\
\text { cycle at } 80 \% \text { depth of discharge, operating } \\
\text { temperature }-30 \text { to } 60 \circ \mathrm{C}, 90-190 \mathrm{Wh} / \mathrm{kg} \text {, } \\
\text { self-discharge } 1 \% / \text { month, high cost due to special } \\
\text { packaging and internal over charge protection. }\end{array}$ \\
\hline
\end{tabular}

\section{Simulation Results and Discussions}

In order to investigate the feasibility of the proposed techniques, UPFC with SMES embedded power flow studies on IEEE 14-bus test system shown in Fig. 4, in this system UPFC with SMES in between bus 1 to 2 or generator 1 to 2 was implemented.

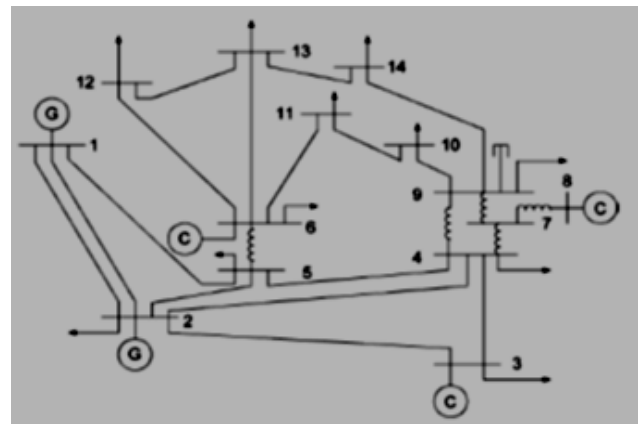

Figure 4. IEEE 14-bus test system

Parameters of the given system are mentions below. Fig.4. shown the MatLab/Simulink model for the test case described above. The generator controller will provide the mechanical input $\mathrm{Pm}$, and the field voltage $\mathrm{V}_{\mathrm{f}}$, depending on the electrical load of the system. The controller will also provide damping to the rotor angle during transient condition of the system. The data for various components used in the simulation are as follows (the values are in pu unless stated).

Synchronous generator parameters: 100MVA, $V=230 \mathrm{KV}$, $f=60 \mathrm{~Hz}, X_{d}=1.305, X_{d}^{1}=0.296, X_{d}^{\prime \prime}=0.255, X q=$ $0.474, X_{q}^{\prime \prime}=0.243, X 1=0.18, X / \mathrm{R}=15$.

Shunt and series Transformer parameter: 100MVA 230 $\mathrm{kV} / 38 \mathrm{kV}, \mathrm{R} 1=0.002, \mathrm{~L} 1=.08, R 2=0.002, L 2=0.08, R m=$ $500, X m=500$.

Transmission line parameters and Nominal $\pi$ network parameter (per $\mathrm{km}$ ): $R 1=0.01273, R 0=0.3864, L 1=$ $0.9337 \mathrm{mH}, L 0=4.1263 \mathrm{mH}, C 1=12.74 \mathrm{nF}, C 0=7.751 \mathrm{nF}$, $\mathrm{L}=500 \mathrm{~km}$.

UPFC parameters: $500 \mathrm{KV}, 100 \mathrm{MVAR}, V \mathrm{dc}=38 \mathrm{KV}$, $\mathrm{Cdc}=2000 \mathrm{e}-6 \mathrm{~F}, V \mathrm{ref}=1.0, K p=12, K i=40$.

Receiving end source (infinite bus): $100 \mathrm{MVA}, V=230 \mathrm{KV}$, $f=60 \mathrm{~Hz}, \mathrm{X} / \mathrm{R}=7, L=1 \mathrm{e}-3 \mathrm{H}, R=0.15 \mathrm{ohms}$.

In the testing system, a symmetrical three phase fault has been applied in transmission line. Transient is created on bus at $0.0167 \mathrm{~s}$ and has been cleared in $0.1 \mathrm{~s}$. In below comparisons shows however stability improvement and the way UPFC with SMES provide higher compensation.

Case (a) is mentioned for the UPFC with battery energy storage system and

Case (b) is mentioned for the UPFC with SMES system.

Compare the Fig.5\&fig.6, Fig.6 is Dynamic response for Voltage the successfully created the stability of power system in $.12 \mathrm{~s}$, although fault cleared in $0.1 \mathrm{~s}$. Here stability of power system is faster case (b) than case (a), that is show in figure. 


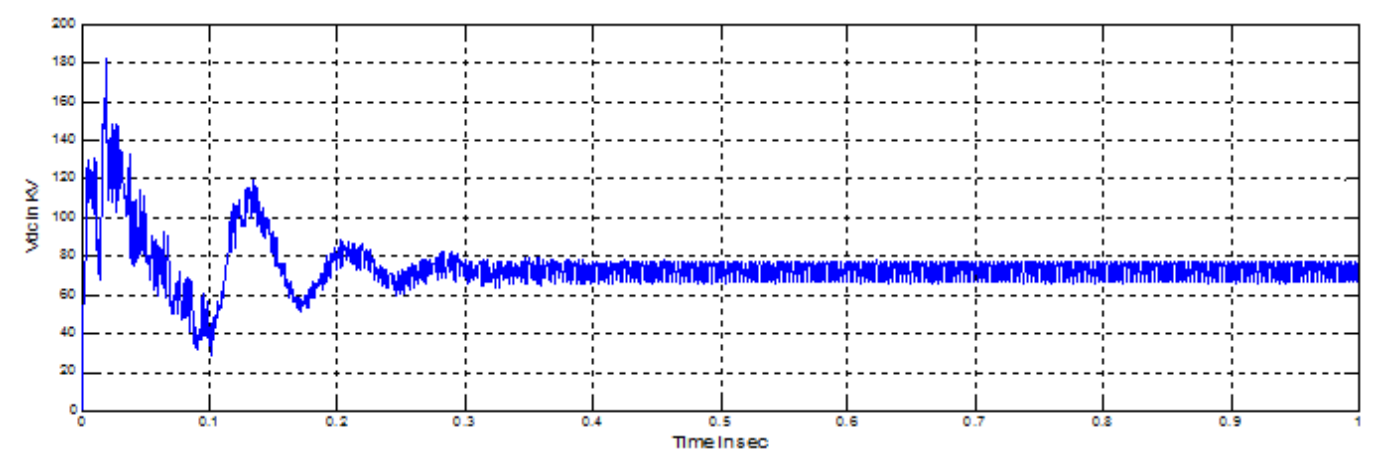

Figure 5. Voltage across DC link capacitor for case (a)

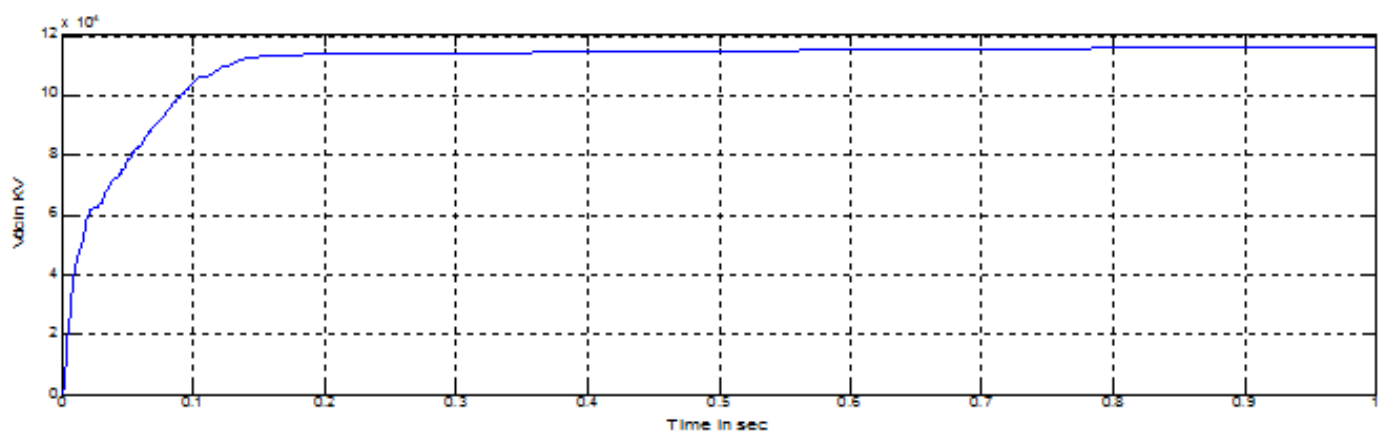

Figure 6. Voltage across DC link capacitor for case (b)
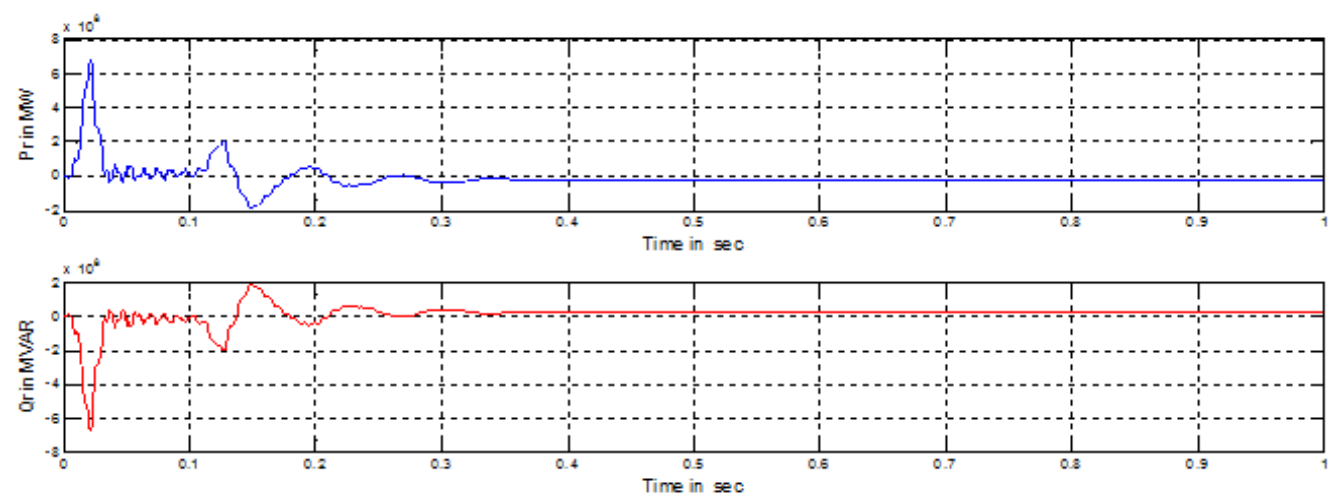

Figure 7. Sending end Real and Reactive power flow over the transmission line for case (a)
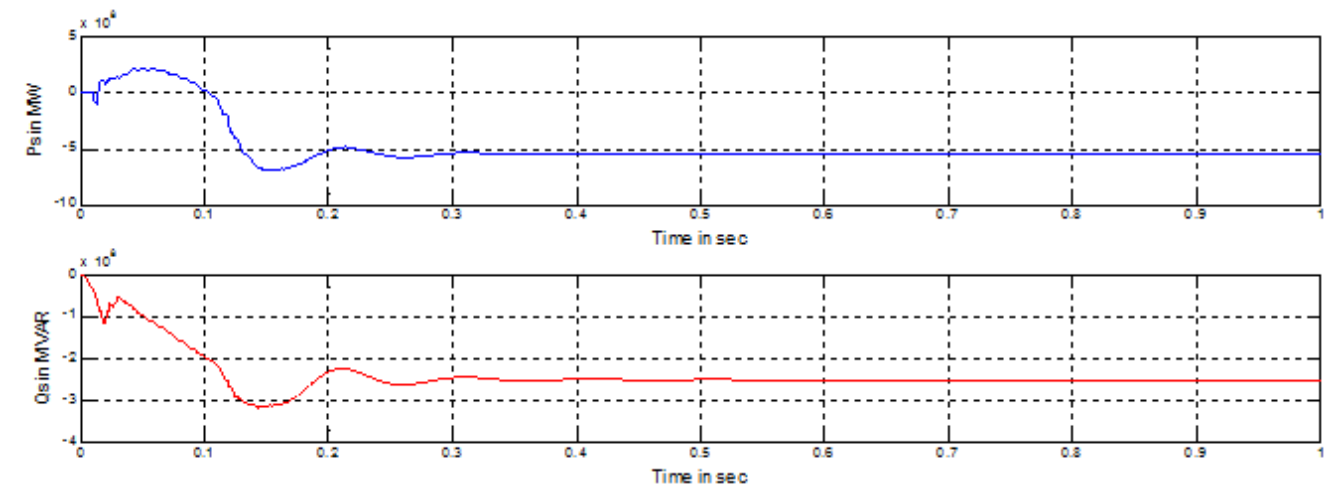

Figure 8. Sending end Real and Reactive power flow over the transmission line for case (b)

Fig.7 and fig.8 shows comparison of real and reactive power of the test system. In these figures, negative real and/or reactive power values represent the injected power from the device to the ac system. After fault clearing, 
amplitude of real and reactive power reduced in case (b) compared with case (a)
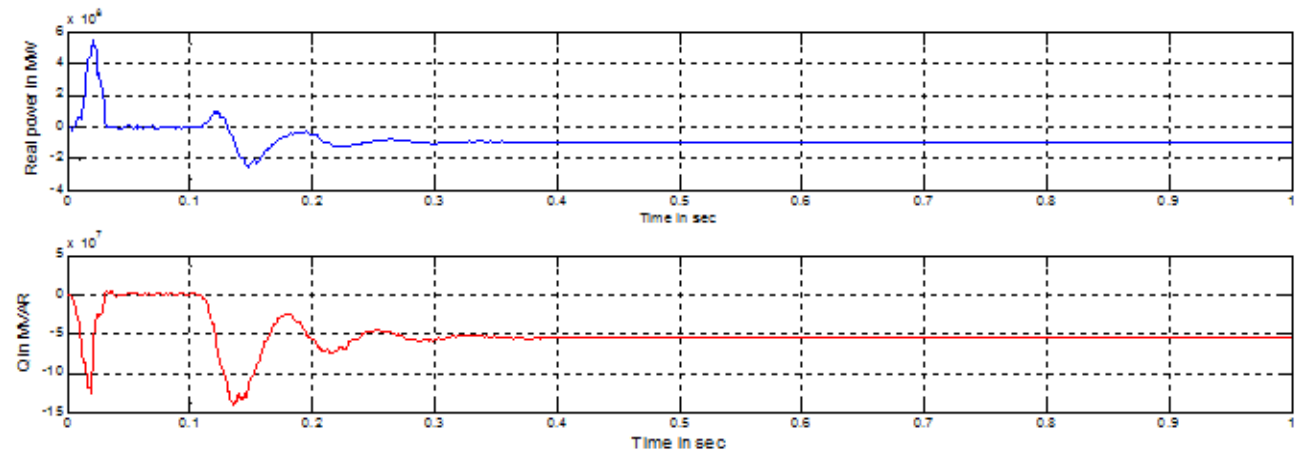

Figure 9. Receiving end Real and Reactive power flow over the transmission line for case (a)
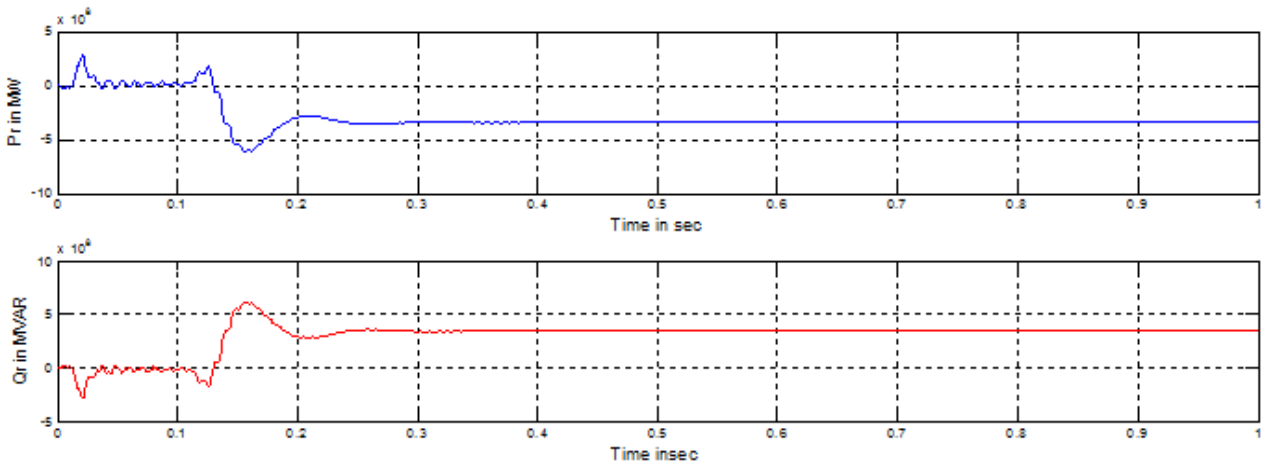

Figure 10. Receiving end Real and Reactive power flow over the transmission line for case (b)

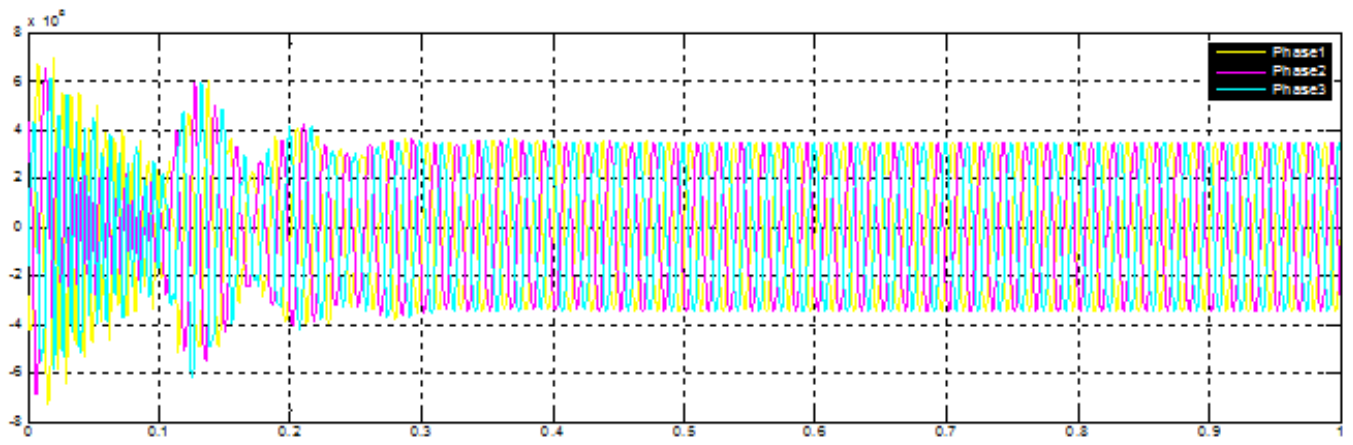

Figure 11. Receiving end voltage Vs Time for case (a)

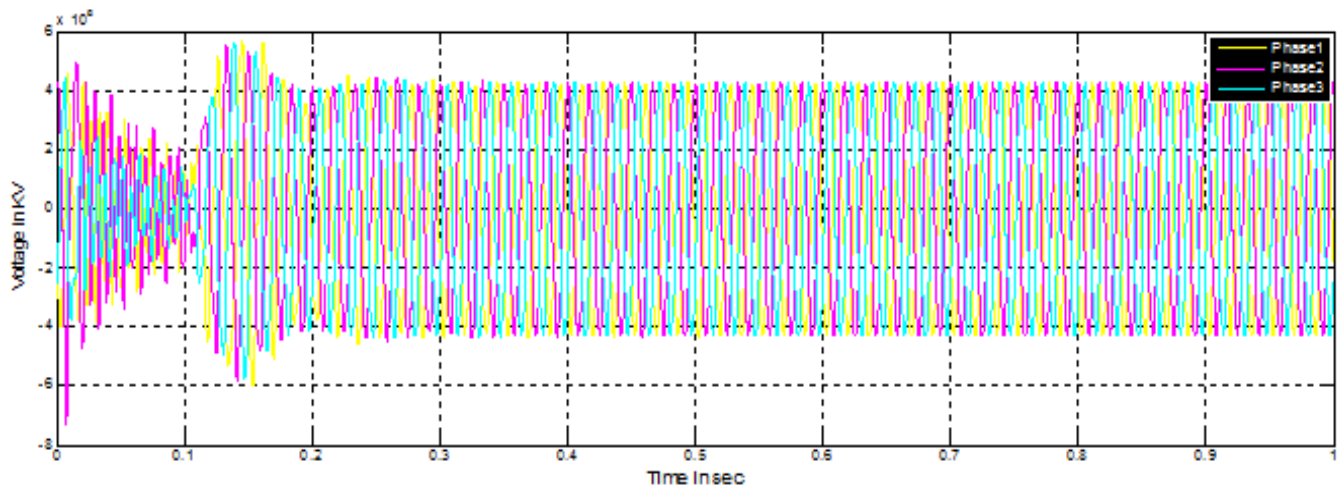

Figure 12. Receiving end voltage Vs Time for case (b)

Fig.9 and fig.10 shows comparison of receiving end real and reactive power of the test system. After fault clearing 
real and reactive power came to stable state take some time. From the comparisons of case (a) and (b), compensation of real and reactive power better in case (b) then the case (a)

Fig.11 and fig.12 shows comparison of three phase voltage of power system. After the fault cleared better performance of the system case (b) then the case (a).

Shows above simulation results are DC Voltage ( $\mathrm{Vdc})$, active power $(\mathrm{P})$ and reactive power $(\mathrm{Q})$ for take a look at system included UPFC with battery and UPFC with SMES. During this UPFC with SMES higher transient stability compensation is provided.

\section{Conclusion}

In this Paper UPFC integrated with SMES and UPFC integrated with battery square measure analyzed exploitation MATLAB /SIMULINK. Throughout these analysis SMES management exploitation two quadrants DC-DC chopper plays a very important role for stability improvement. This planned UPFC with SMES methodology is extremely economical for transient stability improvement, effective power oscillation damping and to take care of power flow in total distance of the conductor when after disturbances. Conjointly the results shown UPFC-SMES integrated system is effective than UPFC-BATTERY integrated system.

\section{References}

[1] N.G.Hingorani, L.Gyugyi. IEEE press, "Understanding FACTS Concepts and Technology of Flexible AC Transmission Systems", 2000.

[2] Paulo F. Ribeiro, Brian K. Johnson, Mariesa L. Crow, AysenArsoy and YILU, "Energy Storage Systems for Advanced Power Applications," proceedings of the IEEE, VOL. 89, NO. 12,2001.

[3] Ali Bidadfar, MehrdadAbedi Mehdi Karari, Chia-Chi Chu. "Power Swings Damping Improvement by Control of UPFC and SMES Based on Direct LyapunovMethodApplication". IEEE Press, 2008.

[4] M. A. Casacca, M. R. Capobianco, and Z. M. Salameh,"Lead-acid battery storage on figurations for improved available capacity,"IEEE Trans. Energy Conversion, vol. 11, pp. 139-145, 1996.

[5] ArindamChakraborty,ShravanaK.Musunuri,Anurag K. Srivastava, and Anil K. Kondabathini,"Integrating STATCOM and Battery Energy Storage System for Power SystemTransient Stability: A Review and Application",Hindawi Publishing Corporation Advances in Power Electronics , Article ID 676010, 12 pages doi:10.1155/2012/676010, 2012.

[6] Z. Yang, C. Shen, L. Zhang, M. L. Crow, and S. Atcitty, "Integration of a StatCom and battery energy storage," IEEE Transactions on Power Systems, vol. 16, no. 2, pp. 254-260, 2001.

[7] K.C. Divya, Jacob Østergaard, "Battery energy storage technology for power systems - an overview", Electric Power Systems Research, Elsevier B.V, 2008.
[8] MahyarZarghami, Mariesa L. Crow, JagannathanSarangapani, Yilu Liu, StanAtcitty, “A Novel Approach to Interarea Oscillation Damping by Unified Power Flow Controllers Utilizing Ultra capacitors ," IEEE Transactions on Power Systems, vol. 25, no. 1, 2010.

[9] P.G. Therond, I. Joly, M. Volker, "Superconducting magnetic energy storage (SMES) for industrial applications-Comparison with battery systems," IEEE Trans. Applied Superconductivity, vol. 3, pp. 250-253, 1993.

[10] M. Parizh, A. K. Kalafala, R. Wilcox, "Superconducting magnetic energy storage for substation applications", IEEE Trans. Applied Superconductivity, vol. 7, no. 2, pp. 849-852, 1997.

[11] C. A. Luongo, "Superconducting storage systems: An overview," IEEE Trans. Magnetics, vol. 32, no. 4, pp. 2214-2223, 1996.

[12] A.B .Arsoy, Y. Liu, P .F .Ribeiro, "Static Synchronous compensatorsand superconducting magnetic energy storage systems in controllingpower system dynamics", IEEE Industry Applications Magazine, 2003.

[13] Antonio Griffo, DavideLauria, "Superconducting Magnetic EnergyStorage Control Strategy for Power System Stability Improvement",Bepress, volume 4, Issue 1, 2005.

[14] IssarachaiNgamroo, "Robust Freqency Stablization By Coordinated Superconducting Magnetic Energy Storage with Static SynchronousSeries Compensator", Bepress, volume 3, Issue 1, Article 1031, 2005.

[15] A. Kazemi, S. Jamali, and H. Shateri, "Effects of SMES Equipped UPFC on Measured Impedance at Relaying Point in Inter Phase Faults", IEEE Electrical Power \& Energy Conference, 978-1-4244-2895-3, 2008.

[16] Sandia national laboratory: http://www.sandia.gov/ess.

[17] Renewable energy systems design assistant for storage: http://www.ecn.nl/resdas.

[18] Electricity storage association: http://electricty-storage.org.

[19] J. X. Jin, High temperature superconducting energy storage technologies: principle and application, Beijing: Science Press, 2011.

[20] J. Tian, Y. Q. Zhu, and C. H. Chen, "Application of energy storage technologies in distributed generation," Electrical technology, no. 8, pp.29-32, 2010.

[21] Y. Li, J. Y. Liu, and C. Hu, "Application and prospect of superconducting energy storage technology in the power system,"Sichuan Electric Power Technology, vol. 32, pp. 33-37, December, 2009.

[22] J. M. Miller, "Trends in vehicle energy storage systems: batteries and ultracapacitors to unite," 2008 Vehicle Power and Propulsion Conference, pp. 1-9, Sept. 3-5, 2008.

[23] A. Khamis, Z. M. Badarudin, A. Ahmad, A. A. Rahman, and M. H. Hairi, "Overview of mini scale compressed air energy storage system," 2010 4th International Power Engineering and Optimization Conference (PEOCO), pp. 458-462, June 23-24, 2010.

[24] T. Nanahara, and A. Takimoto, "A study on required reservoir size for pumped hydro storage," IEEE Transactions on Power Systems, vol. 9, no. 1, pp. 318-323, Feb., 1994. 
[25] K. J. C. M. Posthumus, R. A. A. Schillemans, and E. C. Kluiters, "Sodium-sulphur batteries for naval applications," Eleventh Annual Battery Conference on Applications and Advances, pp. 301-306, Jan. 9-12, 1996.

[26] T. M. Masaud, L. Keun, and P. K. Sen, “An overview of energy storage technologies in electric power systems: What is the future?," North American Power Symposium (NAPS), pp. 1-6, Sept. 26-28, 2010.

[27] L. Zhang, C. Shen, M. L. Crow, L. Dong, S. Pekarek, and S.Atcitty, "Performance indices for the dynamic performance of FACTS and FACTS with energy storage," Electric Power Components and Systems, vol. 33, no. 3, pp. 299-314, 2005.

[28] Y. Cheng and M. L. Crow, "A diode-clamped multi-level inverter for the StatCom/BESS," in Proceedings of the IEEE Power Engineering SocietyWinter Meeting, vol. 1, pp. 470-475,January, 2002.

[29] R. Kuiava, R. A. Ramos, and N. G. Bretas, "Control design of a STATCOM with energy storage system for stability and power quality improvements," in Proceedings of the IEEE International Conference on IndustrialTechnology (ICIT '09), pp. 1-6, February, 2009.

[30] C. Qian, M. L. Crow, and S. Atcitty, "A multi-processor control system architecture for a cascaded StatCom with energy storage," in Proceedings of the 19th Annual IEEE Applied Power Electronics Conference and Exposition (APEC '04), pp.1757-1763, February, 2004. 